\title{
MENINGKATKAN KUALITAS PELAYANAN FISKUS, UNDANG-UNDANG PERPAJAKAN DENGAN SANKSI PERPAJAKAN SEBAGAI VARIABEL MODERATING TERHADAP WAJIB PAJAK ORANG PRIBADI DIKANTOR PELAYANAN PAJAK
}

\author{
Hesti Widi Astuti ${ }^{1}$, Nuzleha ${ }^{2}$, Yuliana Yamin ${ }^{3}$, Ade Sandra Dewi ${ }^{4}$ \\ Universitas Sang Bumi Ruwa Jurai \\ hesti172112@gmail.com,nuzlehahadjar1970@gmail.com,yuliyamin0607@gmail.com, \\ 142.adedewi@gmail.com
}

\begin{abstract}
Abstrak
Tujuan penelitian ini adalah menentukan kualitas pelayanan fiskus mempengaruhi kepatuhan wajib pajak orang pribadi di KPP Pratama Tanjung Karang, menentukan undang-undang perpajakan mempengaruhi kepatuhan wajib pajak orang pribadi Di KPP Tanjung Karang, menentukan kualitas pelayanan fiskus pajak, undangundang perpajakan dan sanksi perpajakan mempengaruhi kepatuhan wajib pajak orang pribadi Di KPP Tanjung Karang. Populasi yang diambil adalah jumlah wajib pajak orang pribadi lapor SPT Tahunan di KPP Tanjung Karang yang berjumlah 25610 orang. Pengambilan sampel menggunakan rumus Slovin yaitu berjumlah 100responden. Hasil uji secara parsial antara variabel kualitas pelayanan fiksus dengan kepatuhan wajib pajak orang pribadi di KPP Tanjung Karang dengan menggunakan uji t, diperoleh nilai thitung $(-1,907)>$ tabel $(-1,984)$ maka Ha diterima, atau dengan kata lain kualitas pelayanan fikus berpengaruh terhadap kepatuhan wajib pajak orang pribadi di KPP Tanjung Karang, hasil uji parsial antara variabel undang-undang perpajakan dengan kepatuhan wajib pajak orang pribadi di KPP Tanjung Karang diperoleh thitung $(0,624)<$ tabel $(1,984)$ maka Ha ditolak, atau dengan kata lain undang-undang perpajakan tidak berpengaruh terhadap kepatuhan wajib pajak orang pribadi di KPP Tanjung Karang, hasil pengujian pengaruh secara simultan dengan menggunakan uji F, diperoleh nilai Fhitung $(58,17)>$ Ftabel $(3,09)$ maka Ha diterima, dengan demikian dapat disimpulkan bahwa hipotesis yang menyatakan kepatuhan wajib pajak orang pribadi, undang-undang perpajakan dan sanksi perpajakan sebagai variabel moderating secara bersama-sama berpengaruh terhadap kepatuhan wajib pajak orang pribadi Di KPP Tanjung Karang dapat diterima kebenarannya.
\end{abstract}

Kata Kunci: Kualitas Pelayanan Fiskus, Undang-Undang Perpajakan, Sanksi Perpajakan, Kepatuhan Wajib Pajak Orang Pribadi.

\begin{abstract}
The purpose of determining the quality services affects individual taxpayer compliance at Tanjung Karang Tax Office, determining tax laws affecting individual taxpayer compliance At Tanjung Karang Tax Office, determining the quality of tax services, tax laws and tax sanctions affect taxpayer compliance private person at KPP Tanjung Karang. The population taken is the number of individual taxpayers who report the Annual SPT at Tanjung Karang Tax Office, totaling 25610 people. Sampling using the Slovin formula, amounting to 100 respondents. The partial test results between the variables improving the quality of fiksus service with individual taxpayer compliance by using the T test, obtained the value of Tcount $(-1.907)>$ Ttable $(-1,984)$ then Ha is accepted, or in other words, increasing the quality of fikus service has an effect on mandatory compliance. individual tax at Tanjung Karang Tax Office, the results of the partial test between tax law variables and individual taxpayer compliance in Tanjung Karang KPP obtained Thitung (0.624) <Ttabel (1.984) then Ha was rejected, or in other words the tax law was not effect on individual taxpayer compliance at Tanjung Karang Tax Office, the results of testing the effect simultaneously using the F test, obtained the value of Fcount (58.17) > Ftable (3.09) then Ha is accepted, thus it can be concluded that the hypothesis which states increases individual taxpayer compliance, tax laws and tax sanctions as moderating variables collectively affect the compliance of individual taxpayers at KPP Tanjung Karang the truth can be accepted.
\end{abstract}

Keywords: Service quality authorities, tax laws, tax sanctions, compliance individual taxpayers. 


\section{PENDAHULUAN}

Penerimaan negara dibagi menjadi dua sektor yaitu sektor internal dan sektor eksternal. Salah satu sumber penerimaan negara dari sektor internal adalah pajak. Kurang lebih 2/3 penerimaan Negara saat ini bersumber dari pajak. Penerimaan dari sumber daya alam mempunyai umur yang relatif terbatas. Hal ini berbeda dengan pajak yang tidak mempunyai batas umur, terlebih dengan semakin bertambahnya jumlah penduduk.

Pajak menurut Mardiasmo (2016) adalah pajak sebagai penyumbang terbesar dari penerimaan negara, memiliki pengaruh yang sangat besar terhadap keberlangsungan pembangunan sebuah negara meskipun terdapat sektor-sektor lainnya yang juga berkontribusi pada penerimaan sebuah negara. Teknologi informasi dapat meningkatkan fasilitas layanan, sehingga semakin transparan seluruh kegiatan perpajakkan.

Tabel 1. Jumlah Wajib Orang pribadi yang Terdaftar Pada Kantor KPP Tanjung

\begin{tabular}{ccc}
\hline Tahun & Jumlah WP Orang Pribadi Terdaftar & Orang Pribadi Lapor SPT Tahunan \\
\hline $\mathbf{2 0 1 3}$ & 68.309 & 1.322 \\
\hline $\mathbf{2 0 1 4}$ & 72.933 & 5.977 \\
\hline $\mathbf{2 0 1 5}$ & 78.583 & 24.660 \\
\hline $\mathbf{2 0 1 6}$ & 84.264 & 22.610 \\
\hline Total & $\mathbf{3 0 4 . 0 8 9}$ & $\mathbf{5 4 . 5 6 9}$ \\
\hline
\end{tabular}

Sumber: KPP Pratama Tanjung Karang, 2017.

Tabel di atas menunjukkan bahwa masih banyak WP Orang Pribadi yang belum melaporkan SPT Tahunan, terlihat dari jumlah WP Orang Pribadi Terdaftar dengan WP orang Pribadi yang melaporka SPT Tahunan. Fenomena ini merupakan salah satu faktor yang bisa dilihat bagaimana WP Orang Pribadi masih kurang dalam pemahaman pajak baik undang-undang perpajakan, sanksi perpajakan dan ada pelayanan yang diberikan oleh KPP kepada WP untuk memberikan pelayanan yang prima. Pelayanan yang diberikan kepada WP dari KPP adalah dengan adanya fiskus pajak.

Pelayanan fiskus pajak adalah satu salah faktor yang mempengaruhi penerimaan pajak. Pelayanan dikatakan berkualitas apabila pelayanan yang cepat memberikan kepuasan kepada WP. Semakin puas WP terhadap pelayanan perpajakan, semakin luas pemahaman wajib pajak terhadap ketentuan dan perundang-undangan perpajakan, semakin tinggi tingkat kepatuhan perpajakannya (Astari, 2011). Ada lima aspek agar kualitas pelayanan memberikan kepuasan bagi pengguna jasa meliputi hal-hal sebagai berikut: (1) Reliability (keandalan), ( Assurance (jaminan), (3) Empaty (empati), (4) Responsieveness (ketanggapan), (5) Tangible (bukti langsung).

Tindakan fiskus dalam penegakan hukum adalah untuk menjamin agar Wajib Pajak dan calon wajib pajak memenuhi ketentuan undang-undang perpajakkan seperti menyampaikan SPT, pembukuan dan informasi lainnya serta membayar pajak pada waktunya. Penegakan hukum dalam ketidak patuhan adalah sanksi administrasi dan denda.

Perumusan masalah dalam penelitian ini adalah sebagai berikut: apakah kualitas pelayanan fiskus berpengaruh terhadap kepatuhan wajib pajak orang pribadi di KPP Pratama tanjung karang?; apakah undang-undnag perpajakkan berpengaruh terhadap kepatuhan wajib pajak orang pribadi di KPP Tanjung Karang?; apakah kualitas pelayanan fiskus, undangundang perpajakan dan sanksi perpajakan berpengaruh terhadap kepatuhan wajib pajak orang pribadi Di KPP Tanjung Karang?. 
Beberapa pengertian kualitas pelayanan pajak adalah sebagai berikut menurut Boediono (2003), kualitas pelayanan pajak adalah suatu proses bantuan kepada wajib pajak dengan caracara tertentu yang memerlukan kepekaan dan hubungan interpersonal agar terciptanya kepuasan dan keberhasilan; menurut Najib (2013), kualitas pelayanan pajak untuk memberikan kenyamanan, keamanan, dan kepastian bagi wajib pajak di dalam pemenuhan kewajiban dan haknya di dalam bidang perpajakan, menurut Pranadata (2014), kualitas pelayanan pajak merupakan salah satu hal yang meningkatkan minat wajib pajak dalam memenuhi kewajiban perpajakannya dan diharapkan petugas pelayanan pajak harus memiliki kompetensi yang baik terkait segala hal yang berhubungan dengan perpajakan di Indonesia; menurut Sapriadi (2013), kualitas pelayanan pajak dapat diartikan sebagai pembandingan antara kualitas pelayanan yang dirasakan konsumen dengan kualitas pelayanan yang diharapkan konsumen; menurut Sapriadi (2013), kualitas pelayanan pajak adalah ukuran citra yang diakui masyrakat mengenai kualitas pelayanan yang diberikan, apakah masyarakat puas atau tidak puas.

Ada lima (5) indikator kualitas pelanayan pajak, yaitu: Keandalan (Reliability) merupakan kemampuan untuk memberikan jasa seperti yang dijanjikan dengan akurat dan terpercaya sesuai yang diharapkan pelanggan yang tercermin dari ketepan waktu layanan yang sama untuk semua orang dan tanpa kesalahan; Ketanggapan (Responsiveness) adalah kemampuan untuk membantu dan memberikan pelayanan yang sebaik mungkin kepada pengguna. Dimensi ini menekankan pada perhatian,kecepatan, dan ketepatan dalam menghadapi permintaan, pertanyaan, complain, dan masalah dari pengguna layanan. Daya tanggap dikomunikasikan pada konsumen; Jaminan (Assurance) adalah pengetahuan karyawan dan kesopanan atau keramahan, kemampuan perusahaan serta karyawannya untuk menumbuhkan rasa percaya pelanggan kepada perusahaan,yang mencakup pengetahuan, kemampuan, kesopanan,dan sifat dapat dipercaya yang dimiliki para staf, bebas dari bahaya risiko atau keraguan-keraguan; Empati (Emphaty) merupakan perhatian tulus, kepedulian, yang diberikan kepada pelanggan yang meliputi kemudahan dalam melakukan hubungan komunikasi yang baik, perhatian pribadi, dan memahami kebutuhan pelanggan.Pelanggan ingin perusahaan memahmi mereka dan sangat penting bagi perusahaan mereka; Bukti Langsung (Tangible) didefinisikan sebagai berikut penampilan fasilitas fisik, peralatan, personal, dan alat komunikasi. Semua peralatan itu mewakili pelayanan secara fisik atau memberikan image pelayanan yang akan digunakan oleh penguna untuk mengevaluasi kualitas.

Pemerintah menciptakan sistem perpajakan yang baru yaitu dengan lahirnya Undangundang Perpajakan baru; yang terdiri atas; UU No.6 tahun 1983 tentang Ketentuan Umum dan Tata Cara Perpajakan, UU No.7 tahun 1983 tentang Pajak Penghasilan dan UU No.8 tahun 1983 tentang Pajak Pertambahan Nilai Barang dan Jasa dan Pajak penjualan atas Barang Mewah, UU No.12 tahun 1985 tentang Pajak Bumi dan Bangunan dan UU No.13 tahun 1985 tentang Bea Materai.

Undang-undang tentang Ketentuan Umum dan Tata Cara Perpajakan (UU KUP) yang dilandasi falsafah Pancasila dan Undang-undang Dasar 1945, didalamnya tertuang ketentuan yang menjunjung tinggi hak warga negara dan menempatkan kewajiban perpajakan sebagai kewajiban kenegaraan. Undang-undang ini memuat ketentuan umum dan tata cara perpajakan yang ada prinsipnya diberlakukan bagi undang-undang pajak material, kecuali dalam undangundang pajak yang bersangkutan telah mengatur sendiri mengenai ketentuan umum dan tata cara perpajakannya.

Sistem, mekanisme, dan tata cara pelaksanaan hak dan kewajiban perpajakan yang sederhana menjadi ciri dan corak dalam pembuatan Undang-Undang ini dengan tetap menganut 
sistem self assessment. Perubahan tersebut khususnya berkaitan dengan peningkatan keseimbangan hak dan kewajiban bagi masyarakat Wajib pajak sehingga masyarakat Wajib Pajak dapat melaksanakan hak dan kewajiban perpajakannya dengan lebih baik. Dasar hukum Ketentuan Umum dan Tata Cara Perpajakan adalah Undang-undang No.6 Tahun 1983 sebagaimana telah diubah terkhir dengan Undang-undang No. 16 Tahun 2009.

Seorang wajib pajak akan memenuhi kewajiban perpajakannya bila memandang bahwa sanksi perpajakan akan lebih banyak merugikannya. Sanksi perpajakan dapat diukur sebagai berikut: 1) Sanksi administrasi; sanksi Administrasi dikenakan bagi pelanggaran aturan perpajakan ringan, dalam undang - undang perpajakan sanksi administrasi dapat dibedakan dalam 3 kelompok yaitu: a) Denda; denda dikenakan terhadap keterlambatan pelaporan atau penyampaian surat pemberitahuan (SPT) Pajak penghasilan (PPh), tidak membuat faktur pajak atau membuat tetapi tidak tepat waktu, tidak mengisi faktur pajak, melaporkan tidak sesuai masa penerbitan faktur pajak (PPn).; b) Bunga; bunga dikenakan terhadap pajak yang tidak atau kurang bayar; c) Kenaikan; kenaikan dikenakan terhadap hasil pemeriksaan terkait dengan pengungkapan ketidak benaran yang berhubungan dengan pembukuan, data SPT yang tidak benar, NPWP, jabatan, kewajiban terkait pemeriksaan, tidak menyampaikan SPT dan sebagainya; 2) Sanksi Pidana; Dikenakan bagi pelanggaran aturan pajak cukup berat. Sanksi pidana dikenakan sehubungan dengan pelanggaran terhadap peraturan perundang- undangan perpajakan khususnya yang tercantum dalam ketentuan umum dan tata cara perpajakan Siti Resmi, (2009).

kepatuhan wajib pajak juga dikemukakan oleh Kiryanto (2000), seperti dikutip oleh Jatmiko (2006) yang menyatakan suatu iklim kepatuhan wajib pajak adalah: 1) Wajib pajak paham dan berusaha memahami UU Perpajakan; 2) Mengisi formulir pajak dengan benar; 3) Menghitung pajak dengan jumlah yang benar; 4) Membayar pajak tepat pada waktunya. Internal Revenue Service (Brown dan Maznur, 2003) mengelompokkan kepatuhan wajib pajak terdiri dari 3 tipe kepatuhan: (1) Kepatuhan penyerahan SPT (filling compliance), (2) kepatuhan pembayaran (Payment complianc), (3) Kepatuhan pelaporan (reporting compliance). Ketiga tipe kepatuhan tersebut dapat diukur secara bersama-sama akan memberikan gambaran yang komperhensif tentang kepatuhan wajib pajak. Namun demikian kepatuhan perpajakan juga menuntut keikutsertaan aktif wajib pajak dalam menyelenggarakan perpajakannya sebab Sebagian besar pekerjaan dalam pemenuhan kewajiban perpajakan itu dilakukan sendiri oleh wajib pajak atau dengan bantuan praktisi perpajakan profesional.

Hipotesis dalam penelitian ini adalah diduga kualitas pelayanan fiskus berpengaruh terhadap kepatuhan wajib pajak orang pribadi di KPP tanjung karang,diduga undang-undang perpajakan berpengaruh terhadap kepatuhan wajib pajak orang pribadi di KPP tanjung karang, diduga kualitas pelayanan fiskus, undang-undang perpajakan dan sanksi perpajakan berpengaruh terhadap kepatuhan wajib pajak orang pribadi di KPP tanjung karang.

\section{METODE PENELTIAN}

Populasi adalah suatu kelompok yang terdiri dari objek atau subjek yang mempunyai kualitas dan karakteristik tertentu yang ditetapkan oleh peneliti untuk dipelajari dan ditarik kesimpulan (Sugiyono, 2014). Populasi yang diambil adalah jumlah wajib pajak orang pribadi lapor SPT Tahunan di KPP Tanjung Karang yang berjumlah 25610 orang.

Pengambilan sampel menggunakan rumus Slovin (Sugiyono, 2014), yaitu: 
Seminar Nasional Penelitian dan Pengabdian kepada Masyarakat Universitas Sang Bumi Ruwa Jurai Tahun 2020

$$
\begin{aligned}
& \mathrm{n}=\frac{N}{1+N \mathrm{e}^{2}} \\
& \mathrm{n}=\frac{25610}{1+25610 \times 0.10^{2}} \\
& \mathrm{n}=\frac{25610}{257,1}=99,61 \text {, dibulatkan } 100 \text { responden }
\end{aligned}
$$

Keterangan:

$\mathrm{n}=$ Jumlah Sampel.

$\mathrm{N}=$ Jumlah Populasi.

$\mathrm{e}=$ Persen kelonggaran ketidak telitian karena kesalahan pengambilan sampel.

Pada penelitian ini e $=10 \%$, maka perhitungan besarnya sampel adalah sebagai berikut:

Cara penentuan sampel dengan menggunakan metode aksidental, yaitu teknik penentuan sampel berdasarkan kebetulan, siapa saja yang secara kebetulan bertemu dengan penelitian dapat digunakan sebagai sampel,bila di pandang orang yang kebetulan ditemui itu cocok sebagai sumber data (Sugiyono, 2014).

Teknik pengumpulan data menggunakan metode survey yaitu pengambilan data secara langsung maupun tidak langsung terhadap objek penelitian mengenai masalah yang di teliti. Melihat situasi dan kondis Wajib Pajak (WP) yang ditemui sehingga bisa mendapatkan data primer melalui kuesioner. Kuesioner adalah pengumpulan data yang dilakukan melalui pengisian kuesioner secara langsung terhadap responden yang telah ditentukan sebagai sampel penelitian.

Uji validitas adalah suatu ukuran yang menunjukkan tingkat - tingkat kevalidan atau ketepatan suatu instrument (Sugiyono, 2014). Standar validitas yang dapat diterima adalah > 0,30. Uji reliabilitas adalah untuk mengukur sejauh mana alat ukur yang digunakan dapat dipercaya artinya bila alat ukur tersebut diujikan berkali-kali hasilnya tetap. Standar reliabilitas yang dapat diterima adalah jika alpha $>0,60$. Model regresi yang digunakan dalam penelitian ini adalah analisis regresi linear berganda. Analisis regresi linear berganda dilakukan dengan tujuan untuk mengetahui arah pengaruh variabel bebas terhadap variabel terikat, apakah pengaruhnya positif atau negatif. Adapun persamaan regresi linear berganda dalam penelitian ini adalah sebagai berikut (Ghozali, 2013) :

$$
Y=a+b_{1} X_{1}+b_{2} X_{2}+b_{3} X_{3}+e_{t}
$$

Keterangan :

$\mathrm{Y}=$ Kepatuhan Wajib Pajak Orang Pribadi

a $\quad=$ Konstanta

$b_{1}, b_{2}, b_{3}=$ koefisien regresi $X_{1}$, koefisien regresi $X_{2}$, koefisien regresi $X_{3}$.

$\mathrm{X}_{1} \quad=$ Kualitas pelayanan fiskus $\mathrm{X}_{2}$

$=$ Undang-undang perpajakan $\mathrm{X}_{3}=$

Sanksi perpajakan

$\mathrm{e}_{\mathrm{t}} \quad=$ error term

\section{HASIL DAN PEMBAHASAN}


Hasil dari uji Validitas untuk variabel kualitas pelayanan fikus pajak, undang-undang perpajakan, sanksi perpajakan dan kepatuhan wajib pajak orang pribadi adalah valid karena nilai pada kolom Pearson Correlation di atas 0,3.

Hasil dari Uji Reliabilitas dengan Cronbach's Alpha untuk varibel kualitas pelayanan fikus pajak, undang-undang perpajakan, sanksi perpajakan dan kepatuhan wajib pajak orang pribadi berada di atas batas minimal yaitu sebesar 0,60 maka pernyataan semua variable reliabel.

Analisis regresi linier berganda dimaksudkan untuk mengetahui besarnya pengaruh variabel bebas terhadap variabel terikat yaitu dengan menggunakan analisis regresi linier berganda, dari hasil pengolahan data dengan menggunakan program komputer SPSS 20 for windows yaitu sebagai berikut:

Tabel 2. Hasil Uji Regresi Linear Berganda

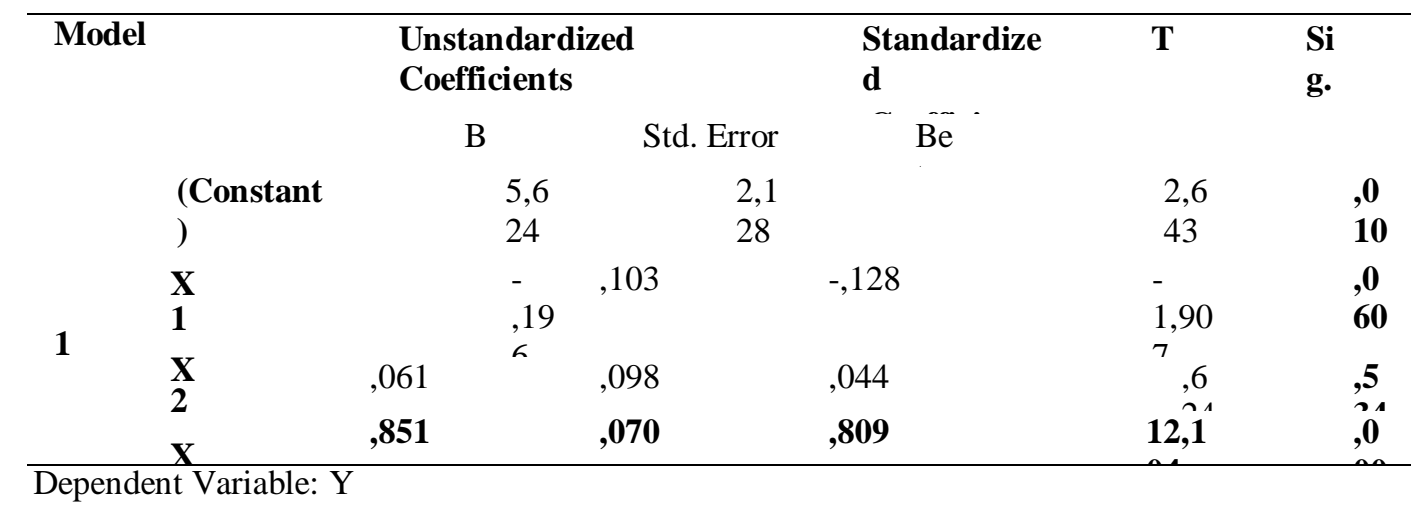

Sumber: Data Diolah, 2020.

Hasil di atas, kemudian dimasukan ke dalam bentuk persamaan regresi linier berganda, sehingga menjadi persamaan sebagai berikut:

$$
Y=5,624-0,196 X_{1}+0,061 X_{2}+0,851 X_{3}+\text { et }
$$

Arti dari persamaan regresi linier adalah sebagai berikut:

- $\mathrm{a}$ (konstanta) $=5,624$ berarti jika tidak ada nilai kualitas pelayanan fiskus, undangundang perpajakan dan sanksi perpajakan maka kepatuhan wajib pajak orang pribadi akan tetap sebesar 5,624.

- $b_{1}=-0,196$, berarti jika ada perubahan nilai kualitas pelayanan fiksus sebesar 1 satuan maka akan mempengaruhi kepatuhan wajib pajak orang pribadi sebesar -0,196.

- $\mathrm{b}_{2}=0,061$, berarti jika ada perubahan nilai undang-undang perpajakan sebesar 1 satuan maka akan mempengaruhi kepatuhan wajib pajak orang pribadi sebesar 0,061.

- $\mathrm{b}_{3}=0,851$, berarti jika ada perubahan nilai sanksi perpajakan sebesar 1 satuan maka akan mempengaruhi kepatuhan wajib pajak orang pribadi sebesar 0,851.

Hasil uji secara parsial antara variabel kualitas pelayanan fiskus dengan kepatuhan wajib pajak orang pribadi dengan menggunakan uji $t$, diperoleh nilai $t_{\text {hitung }}(-1,907)>t_{\text {tabel }}(-1,984)$ maka Ha diterima, atau dengan kata lain kualitas pelayanan fiskus berpengaruh terhadap kepatuhan wajib pajak orang pribadi. Hasil uji parsial antara variabel undang-undang perpajakkan dengan kepatuhan wajib pajak orang pribadi diperoleh $t_{\text {hitung }}(0,624)<t_{\text {tabel }}$ $(1,984)$ maka Ha ditolak, atau dengan kata lain undang-undang perpajakan tidak berpengaruh terhadap kepatuhan wajib pajak orang pribadi. 
Seminar Nasional Penelitian dan Pengabdian kepada Masyarakat Universitas Sang Bumi Ruwa Jurai Tahun 2020

Hasil pengujian pengaruh secara simultan dengan menggunakan uji $\mathrm{F}$, diperoleh nilai $\mathrm{F}_{\text {hitung }}(58,17)>\mathrm{F}_{\text {tabel }}(3,09)$ maka Ha diterima, dengan demikian dapat disimpulkan bahwa hipotesis yang menyatakan kualitas pelayanan fiskus, undang-undang perpajakan dan sanksi perpajakan secara bersama-sama berpengaruh terhadap kepatuhan wajib pajak orang pribadi dapat diterima kebenarannya.

\section{KESIMPULAN}

Kesimpulan dalam penelitian ini adalah sebagai berikut:

a. Hasil uji secara parsial antara variabel kualitas pelayanan fiskus dengan kepatuhan wajib pajak orang pribadi dengan menggunakan uji $t$, diperoleh nilai $t_{\text {hitung }}(-1,907)>t_{\text {tabel }}(-1,984)$ maka Ha diterima, atau dengan kata lain kualitas pelayanan fiskus berpengaruh terhadap kepatuhan wajib pajak orang pribadi.

b. Hasil uji parsial antara variabel undang-undang perpajakkan dengan kepatuhan wajib pajak orang pribadi diperoleh $t_{\text {hitung }}(0,624)<\mathrm{t}_{\text {tabel }}(1,984)$ maka Ha ditolak, atau dengan kata lain undang-undang perpajakkan tidak berpengaruh terhadap kepatuhan wajib pajak orang pribadi.

c. Hasil pengujian pengaruh secara simultan dengan menggunakan uji $\mathrm{F}$, diperoleh nilai $\mathrm{F}_{\text {hitung }}$ $(58,17)>\mathrm{F}_{\text {tabel }}(3,09)$ maka Ha diterima, dengan demikian dapat disimpulkan bahwa hipotesis yang menyatakan kualitas pelayanan fikus, undang-undang perpajakkan dan sanksi perpajakkan secara bersama-sama berpengaruh terhadap kepatuhan wajib pajak orang pribadi dapat diterima kebenarannya.

\section{DAFTAR PUSTAKA}

Astari, D., I., (2011). "Pengaruh Tingkat Kepuasan Pelayanan, Pemahaman Perpajakan, Keadilan Perpajakan dan Kesadaran Perpajakan Terhadap Tingkat Kepatuhan Wajib Pajak Orang Pribadi Di KPP Tg.Pinang Kepulauan Riau”.

Boediono. (2003). Pelayanan Prima Perpajakan. PT. Rineka Cipta, Jakarta.

Brown, R., E., dan Mazur, M., J., (2003). IRS's Comprehensive Approach to Compliance

Measurement. (2006). National Tax Journal. http://www.pajak.go.id https://www.pojokpajak.wikia.com/wiki/undang-undang_Ketentuan_Umum_Perpajakan. Jatmiko, N., A., 2006, Pengaruh Sikap Wajib Pajak Pada Pelaksanaan Sanksi Denda,

Pelayanan Fiskus dan Kesadaran Perpajakan Terhadap Kepatuhan Wajib Pajak (Studi Empiris Terhadap Wajib Pajak Orang Pribadi di Semarang). Tesis Program S2 Magister Akuntansi Universitas Diponegoro. Tidak Dipublikasikan.

Kiryanto. (2000) Analisis Pengaruh Penerapan Struktur Pengendalian Intern Terhadap Kepatuhan Wajib Pajak Badan Dalam Memenuhi Kewajiban Pajak Penghasilannya. EKOBIS, Vol. 1 No. 1, hlm. 41 - 52.

Mardiasmo (2016) Perpajakan, Andi Offset, Yogyakarta.

Najib, F.,D. (2013) Analisis Faktor-faktor Yang Mempengaruhi Kepatuhan Wajib Pajak Orang Pribadi dalam Membayar Pajak Penghasilan,Skripsi Fakultas Ekonomi Universitas Brawijaya, Malang. 
Seminar Nasional Penelitian dan Pengabdian kepada Masyarakat Universitas Sang Bumi Ruwa Jurai Tahun 2020

Pranadata, I.,G., P. (2014) Pengaruh Pemahaman Wajib Pajak, Kualitas Pelayanan Perpajakan Dan Pelaksanaan Sanksi Pajak Terhadap Kepatuhan Wajib Pajak Orang Pribadi Pada KPP Pratama batu, Skripsi Universitas Brawijaya.

Resmi, S. (2009). Perpajakan: Teori dan Kasus. Yogyakarta : Salemba Empat

Sapriadi, D. (2013) Pengaruh Kualitas Pelayanan Pajak, Sanksi Pajak dan Kesadaran Wajib Pajak Terhadap Kepatuhan Wajib Pajak Dalam Membayar PBB (Pada Kecamatan Selupu Rejang), Skripsi Fakultas Ekonomi Universitas Negeri Padang.

Sugiyono. (2014). Metode Penelitian Pendekatan Kuantitatifm kualitatif dan $R \&$ D. Bandung: Alfabet 